\title{
The information needs of music therapists: challenges of assessment in the clinical setting
}

\author{
Allison Richardson and Dean Giustini
}

\begin{abstract}
Objective - This paper explores various methods that librarians can use to evaluate and meet the information needs of clinical music therapists (MTs). Methods - A survey of the literature of music therapy (MT) found many empirical studies of MT but none describing how MTs commonly express and satisfy their information needs. As a means of assessing their information needs, we first examine the basic features of MT practice and then compare MTs' information needs with the well-documented needs of nurses. Results - We believe that MTs and nurses exhibit similar basic information needs, such as access to $(i)$ colleagues and experts; (ii) current information in print, electronic, and alternate formats; (iii) reference and ILL assistance from librarians; and (iv) library training to search databases and catalogues. Conclusions - Librarians should collaborate with MTs to identify their specific information needs. To begin, library services can be built by allocating relatively few resources. To evaluate what is required in evidence-based MT, librarians and MT associations should administer a national needs-assessment survey or questionnaire.
\end{abstract}

\section{Introduction}

Music therapy (MT) — what is it, how does it work, and how can health libraries support the information needs of its practitioners? Currently, no one has yet published a study focused exclusively on the information needs of music therapists. This investigation attempts to fill in some gaps in professional knowledge by examining the relevant literature, reviewing MT practice and theory, and comparing clinical MT practice with studies of nursing information needs; our goal is to reveal some of the challenges MTs face in fulfilling their own information needs. We continue by addressing issues of library instruction, collection development, and liaison with MTs, outlining a number of simple, inexpensive solutions for provision of service. We conclude by proposing further library research to evaluate and describe the information needs of MTs more systematically.

\section{The search for MT information needs literature}

Because of MT's interdisciplinary nature, we searched 16 bibliographic databases for relevant information: Library Literature \& Information Science, LISA, MEDLINE/ PubMed, NLM Gateway, CINAHL, EMBASE, PsycINFO, Academic Search Premier, Digital Dissertation Abstracts, ERIC, Music Index, International Index to Music Periodicals, RILM, CAIRSS, and Music Therapy World. In addition, we also hand-searched several print and online MT

A. Richardson and D. Giustini. ${ }^{1}$ University of British Columbia, Biomedical Branch Library, Vancouver General Hospital, 700 West 10th Avenue, Vancouver BC V5Z 1L5, Canada.

${ }^{1}$ Corresponding author (e-mail: dean.giustini@ubc.ca or giustini@interchange.ubc.ca). journals. However, we found a total of only three relevant articles.

The first article used productivity, citation, and indexing analysis to highlight the challenges of information retrieval in MT and music education (ME). It concluded that researchers in those areas do not necessarily focus on limited agendas and that articles may be indexed under a wide variety of subject headings and keywords [1]. The second described the research processes of music scholars, including some MTs, and noted that MT scholars were more likely to use quantitative, scientific research designs than other music scholars [2]. The third described music educators' information needs when working with challenged students in mainstreamed classrooms (situations similar to those MTs encounter when dealing with challenged or developmentally delayed children). It found that music educators express a need for more information about designing, evaluating, and applying various aspects of music education to challenged students [3].

Examined together, these articles reveal that MTs face a variety of challenges to meeting their information needs. MT is interdisciplinary and MTs need a wide variety of quantitative and qualitative information from both scholarly and popular contexts. Because the information itself is so varied, searching and bringing formats together is likely to be a time-consuming and difficult task. Different information is catalogued under a wide range of subject headings, described by a wide range of keywords, and accessed using several methods. Examination of some of MT's theory and practice further illuminates these observations.

\section{MT in theory and practice}

To extend effective information services, librarians should understand their users' clinical practice and work environment [4]. MTs often feel that MT principles, methods, and 
uses are misunderstood [5]. Some confusion undoubtedly arises from MT's dual role as both a clinical discipline [6] and an alternative to standard care [7]. In addition, MTs are asserting new roles for themselves [8] in both traditional and complementary medicine. Increasing numbers of MT studies are being conducted in the field $[9,10]$, and an emphasis on quantitative methods can be seen in randomized controlled trials [11] and Cochrane reviews [12]. MT is increasingly recognized as a legitimate clinical profession with a set of principles and standards of ethical practice [13].

But what exactly is MT? Perhaps the confusion can be explained by pedagogue and researcher Kenneth Bruscia's distinction between the two uses of music in healing, "music in therapy", and "music as therapy". In "music in therapy", recorded music is played by psychologists, physicians, nurses, or teachers for its beneficial effects on patients [14]. However, in "music as therapy", MT is the primary therapeutic modality - an active musical experience of some kind forms the core of the treatment [14]. A full definition of MT is difficult to formulate, but generally

Music therapy is an interpersonal process in which the therapist uses music and all of its facets - physical, emotional, mental, social, aesthetic, and spiritual - to help clients to improve, restore, or maintain health. In some instances, the client's needs are addressed directly through the elements of music; in others they are addressed through the interpersonal relationships that develop between client and therapist or group. The music used in therapy may be specially created by the therapist or client, or it may be drawn from the existing literature in various styles and periods [15].

A musical experience of some kind, such as improvising, re-creating, composing, or listening to music is central to MT [16]. Therapeutic benefits are derived from the mental, social, physical, physiological, emotional, and spiritual effects of the musical experience. MTs work within one or a combination of paradigms: medical, psychoanalytical, behavioral, or humanistic [17]. While artistic and even creative [18], MT is nonetheless applied using current scientific principles.

MT uses a wide variety of methods in many varied clinical contexts. For example, it is widely used for anxiety problems, emotional and developmental disorders, physical rehabilitation, palliative care, mental illness, geriatric care, and pain management [19]. Typical practice areas include geriatrics, followed by special needs children, palliative care, and mental health. Accordingly, professional MTs liaise with other health professionals across the spectrum of care.

What are some examples of the use of MT? In pediatrics, MT is used to improve the speech, social interaction, selfconfidence, and physical coordination in developmentally delayed children. MTs may decide to treat these patients through musical improvisation on various instruments to inspire movement and promote vocalization - an important step in speech development. At the end of the continuum of care, MTs perform songs with or for palliative care patients, assisting them with life review and end-of-life issues (for a fuller discussion of MT in context, see Bruscia's Case Studies in Music Therapy) [20].

\section{Information needs of nursing: how they compare with MT}

Like many healthcare professionals, MTs face a number of challenges in meeting their information needs. Examination of how other health care professionals find and communicate information can illuminate some of the special challenges facing MTs. Nurses, who are more thoroughly examined in the information needs literature, have several information-seeking patterns worth describing.

Spath and Buttlar's study of nurses' information needs [21] found that the following information seeking methods were regularly employed: asking colleagues (51\%), consulting library catalogues by subject $(45 \%)$, browsing library shelves in subject areas (44\%), asking other experts (40\%), and asking librarians (38\%). Other health professionals employed similar methods in two other studies [22,23].

When examining nurses' preferred information sources, it is not surprising that journals were the most preferred information sources for Spath and Buttlar's subjects (79.4\%), given the importance attached to the currency of health information. The other heavily used information sources were other colleagues $(64.7 \%)$, the library catalogue $(51 \%)$, films or videos $(46.1 \%)$, and conferences $(43.1 \%)$. Another study noted that nurses used a range of oral, written, printed, and computerized information sources in daily practice [24].

To the extent that nurses' information-seeking behaviours represent a snapshot view of information-seeking behaviour in the health sciences, we can note a number of challenges MTs are likely to face when attempting to find and communicate information. Two major obstacles MTs face are working in isolation and in part-time or contract positions. In comparison to nurses, who can consult colleagues in close proximity, only a single or, at most, a very few MTs are likely to be employed by one institution [25], making broad, professional consultation a difficult task. This is related, of course, to funding, as well as a lack of critical mass in the field. In 2001, the Canadian Association for Music Therapy (CAMT) listed only 237 accredited MTs [26].

The ability to consult experts to fulfill information needs is also problematic owing to the small numbers of MTs and to the lack of opportunities for advanced study. Several institutions in the US offer advanced degrees and training, but in Canada, there are no Ph.D. programs and only one master's program, at Wilfred Laurier University in Ontario, Canada. Another effect of working in part-time or contract positions is that the use of temporary employees inhibits full integration into a "hospital culture" [27]. Without full involvement, MTs are less visible, and other health care professionals, including medical librarians, are likely less aware of the principles and practice of MT and their needs. Conversely, MTs may not be fully knowledgeable regarding their facility's library services.

Other challenges arise from the interdisciplinary nature of MT and the use of alternate formats. While $44 \%$ of nurses browse to fulfill their information needs, MTs may find this a less viable method. MT draws from numerous fields, including medicine, nursing, psychology, education, and, of course, music. While hospital libraries may collect in most of those areas, MTs must go elsewhere to browse through library collections that include music (both printed and re- 
corded), education, and interdisciplinary subjects, such as the psychology of music. Furthermore, professional journals - nurses' most-preferred information source - such as The Journal of Music Therapy, Music Therapy Perspectives, and The British Journal of Music Therapy are neither easily nor widely accessible. Although large academic libraries may maintain print subscriptions to these journals, most health libraries will not maintain this type of collection. Many MT journals are not yet available in an online format.

\section{Challenges of accessing the literature}

Some allied health disciplines are able to access large collections of research materials, but others are not as fortunate. MT is not well known and there is a perceived lack of rigorous research. The methodologies used in art therapy (AT) are similar to MT in that they are more often observational and case-based rather than quantitative or qualitative [28]. This means that the literature does not always meet the standards for indexing in the major databases [29].

The MT literature is found in different kinds databases owing to the interdisciplinary nature of the subject. The literature is considered either clinical or complementary in nature. A 1985 study of searching MT literature searched MEDLINE, CINAHL, PsychINFO, and several sociology databases [30]. To be systematic today, ERIC, the Music Index, and the International Index to Music Periodicals should be searched in addition to the medical and allied health databases. Although some researchers cannot access music databases, there are two free alternatives on the Web: CAIRSS and MTW (discussed later in this paper).

Librarian awareness of books published in MT is usually minimal. Some librarians may not have the resources to buy MT books or materials in audio-visual formats. MT textbooks are not included on standard hospital library lists such as Brandon-Hill or Doody's and may be outside the purview of traditional medical publishers. But much useful MT information is embedded in monographs [31]. To bring structure and control to the book literature, librarians should consider setting up Web-based indexes or lists of MT materials that would point to monographs held locally or regionally in their collections as these materials are not likely to be available in traditional bibliographic tools such as MEDLINE or CINAHL.

\section{MT resources}

\section{Databases}

Free, Web-accessible databases such as PubMed.gov and Medlineplus.gov at the NLM provide good basic clinical information for MTs. These tools contain relevant full-text articles and a growing number of MT-specific materials. The development of Web pathfinders for MTs is another costefficient option (and a good teaching tool). Good examples are the American Music Therapy Association (http:// www.musictherapy.org/listserv.html), Lesley University and Temple University (http://www.temple.edu/musictherapy/ dbs.htm). To provide regional or national focus, librarians should consider providing links to appropriate authoritative Web sites [32,33] or general music pathfinders at local col- leges or universities (http://toby.library.ubc.ca/subjects/ subjpage $1 . \mathrm{cfm}$ ?id=58)

MTs can use two freely accessible databases beyond PubMed: (1) The University of Texas at San Antonio's CAIRSS Database (http://imr.utsa.edu/), which indexes literature from music education, music psychology, music therapy, and music medicine; and (2) Music Therapy World (MTW) (http://www.musictherapyworld.de/index.html), which is hosted by the Institute for Music Therapy at the University of Witten/Herdecke in Germany. MTW provides access to numerous free publications, a growing database of structured reviews, bibliographies, and abstracts of dissertations. MTW also has a research registry where World Music Federation members can exchange information and research interests.

\section{Current awareness tools}

The MT community supports a number of discussion boards and listservs that can be recommended [34]. Additionally, librarians may want to provide print or electronic searches and tables of content (TOCs) services to MTs or show them how to set up automatic searches.

\section{Interlibrary loan}

Librarians can help set up effective search strategies and provide interlibrary loan services for items not held locally in their collections. Interlibrary loan (ILL) requests and usage patterns should be reviewed annually and high-use materials (i.e., print, electronic, audiovisual, or other) considered for purchase, provided funds are available.

Occasionally, MTs need to learn songs for hard to find music and lyrics. Local academic or special music libraries may be able to supply these materials. When possible, librarians should consider joining relevant resource-sharing initiatives to obtain music-related ILLs. If ILL services for sheet music cannot be offered, the librarian should help MTs find out where materials can be copied or purchased. In the future, sound files in MP3 or other formats may also be found on the Web.

\section{Collaboration between librarians and MTs}

An effective way of raising awareness of library resources and services is for librarians to speak and (or) present searching workshops at MT conferences. Annual conferences in the US and Canada are logical venues to present papers, posters, and workshops. Provincial or state associations (such as the Music Therapy Association of British Columbia) list related meetings on their Web sites and present further liaison opportunities for librarians.

MTs should be encouraged to contribute materials to their local libraries. The British Columbia Cancer Agency (BCCA) Library in Vancouver, Canada has initiated an effective collaboration in this regard. The Library provides a selection of music and imagery tapes to help patients with relaxation. The Agency's MT recommends tapes for purchase and helps with selection of materials. The library and the MT have produced a number of professionally recorded music and guided imagery relaxation tapes, which are available for loan or sale at the BCCA library [35]. 
Providing patients with listening facilities in the library is a creative option. MTs can work with librarians to design quiet space in the library so that patients have uninterrupted time to listen to music between appointments. This type of service provides patients with some relief from stressful environments and a sense of control while interacting with the health care system.

Finally, librarians should work with their MTs to order materials for purchase [36]. Most MTs are members of professional associations and receive publication notices, which might not otherwise come to the librarian's attention. The BCCA's librarian reports that her relationship with the clinic's MT helps to ensure that current, relevant MT materials are purchased for the library collection [37]. Liaison with MT practitioners will help librarians overcome some of the difficulties of collecting certain materials [38].

\section{Conclusion}

Librarians can meet the challenges of providing information services to MTs by understanding the principles and practices of MT, reading the literature, assessing needs, and liaising with MTs. To more systematically understand information needs, a national survey of MTs should be conducted in collaboration with MT associations. Further case studies would also be welcome additions to the literature. Developing mutually beneficial relationships with new users is an important liaison activity for all health librarians, and critical in the interprofessional era.

\section{References}

1. Brittin R, Stanley JM. Researchers in music education/therapy: an analysis of publications, citations and retrievability of work. J Res Mus Ed. 1997 Spring;45(1):45-60.

2. Brown, C. Straddling the humanities and social sciences: the research process of music scholars. Libr Inf Sci Res. 2002;24(1):73-94.

3. Gilbert PG, Asmus, EP. Mainstreaming: music educators' participation and professional needs. $J$ Res Mus Ed. 1980;29(1):31-7.

4. Blythe J, Royle JA. Assessing nurses' information needs in the work environment. Bull Med Libr Assoc. 1993;81(4):433-5.

5. Bunt L. Music therapy: an art beyond words. London: Routledge; 1994.

6. Ibid.

7. Demur C, Sauer J. Assessing complementary therapy services in a hospice program. Am J Hosp Palliat Care. 2002 SepOct;19(5):306-14.

8. Aldridge D. An overview of music therapy research. Complement Ther Med. Oct 1994 2(4):204-16.

9. Aldridge D. Music therapy research: a review of references in the medical literature [Web page]. 2002 [cited 2 July 2003]. Available from http://www.musictherapyworld.net/modules/archive/stuff/papers/mtreview.pdf.

10. Aldridge, 1994, op. cit.

11. Schiemann U, Gross M, Reuter R, Kellner H. Improved procedure of colonoscopy under accompanying music therapy. Eur J Med Res. 2002;7:131-4.
12. Vink AC, Bruinsma MS, Scholten R. Music therapy in the care of people with dementia. [Protocol] Cochrane Dementia and Cognitive Improvement Group Cochrane Database Syst Rev. 1 [database on the Internet], 2003.

13. Bunt L, Hoskyns S. Practicalities and principles of music therapy. In: The handbook of music therapy. East Sussex, England: Brunner-Routledge; 2002.

14. Bunt, 1994, op. cit.

15. Bruscia K, editor. Case studies in music therapy. Gilsum, (NH): Barcelona Publishers; 1991.

16. Alvin J. Music Therapy. London: Hutchinson; 1975.

17. Bunt, 1994, op. cit.

18. Aldridge D. Music therapy research and practice in medicine: from out of the silence. London: Jessica Kingsley Publishers; 1996.

19. Alvin, op. cit.

20. Bruscia, op. cit.

21. Spath M, Buttlar, L. Information and research needs of acutecare clinical nurses. Bull Med Libr Assoc. 1996;84(1):112-15.

22. Codgill KW. Information needs and information seeking in primary care: a study of nurse practitioners. J Med Libr Assoc. 2003 April;91(2):203-215.

23. Pyne T, Newman K, Leigh S, Cowling A, Rounce K. Meeting the information needs of clinicians for the practice of evidence based healthcare. Health Libr Rev. 1999 Mar;16(1):3-14.

24. Blythe, Royle, op. cit.

25. Music Therapy Association of British Columbia. What is the job market for music therapists? [Web page]. North Vancouver, BC: The Association, 2002 [cited 15 Mar 2003]. Available from http://www.mtabc.com/openingpage.html.

26. Canadian Association for Music Therapy. Accreditation [Web page]. 2001 [cited 15 Mar 2003]. Available from http:// www.musictherapy.ca/.

27. Lopopolo R. The relationship of role-related variables to job satisfaction and commitment to the organization in a restructured hospital environment. Phys Ther. 2002 Oct;82(10):98499.

28. Malchiodi C. Finding art therapy on databases. Art Ther. 1996;13:86-7.

29. Ibid.

30. Lambert M, Brody F. Tailoring search strategy for a highly specialized topic: proof once again of the necessity of using file documentation to the fullest. Database. 1985;8:58-61.

31. Ibid.

32. Calabretta N, Miller B. Recommended core collection of Web sites for hospital libraries. Med Ref Serv Q. 2001 Winter;20(4):1-25.

33. Harris L. Collection management in hospital libraries and the evaluation of Internet resources: a preliminary guide. BMC. Spring 2000;21(3):9-11.

34. American Music Therapy Association. Music therapy and related resources on the World Wide Web [Web page]. Silver Spring, MD: The Association, 1999 [cited 15 Mar 2003]. Available from http://www.musictherapy.org/listserv.html.

35. Morrison B. British Columbia Cancer Agency. Head Librarian. Personal communication, 8 April 2003.

36. Jacoby BE, Murray J, Alterman I, Welbourne P. Resource selection for an interdisciplinary field: a methodology. $J$ Med Libr Assoc. 2002 Oct;90(4):393-9.

37. Morrison, op. cit.

38. Scholman BF. Mapping the literature of allied health: project overview. Bull Med Libr Assoc. 1997 Jul;85(3):271-7. 